\title{
Pemetaan Batimetri dan Sedimen Dasar di Perairan Karangsong, Kabupaten Indramayu, Jawa Barat
}

\author{
Angga Dwi Saputra, Heryoso Setiyono, Agus Anugroho D. S. \\ Program Studi Oseanografi, Fakultas Perikanan dan Ilmu Kelautan, Universitas Diponegoro \\ Kampus Tembalang, Semarang 50275 Telp/Fax. 024-7474698 \\ Email: anggaose@gmail.com
}

\begin{abstract}
Abstrak
Perairan Karangsong adalah wilayah pesisir di Kabupaten Indramayu dan merupakan kawasan penting bagi perekonomian masyarakat setempat. Adanya rencana pengembangan serta perawatan infrastruktur di wilayah Pesisir Karangsong secara berkelanjutan diperlukan adanya penelitian mengenai batimetri, kelerengan perairan dan sedimen dasar. Tujuan dari penelitian adalah untuk mengetahui kedalaman perairan, profil perairan, kelerengan serta jenis sedimen dasar di Perairan Karangsong. Metode yang digunakan dalam penelitian adalah metode kuantitatif. Metode pengambilan data kedalaman dan sedimen dasar dilakukan di wilayah yang dianggap mewakili kerakteristik wilayah seluruhnya. Hasil penelitian menunjukkan kedalaman Perairan Karangsong, Kabupaten Indramayu berkisar antara 1 meter sampai 11 meter dengan nilai kelerengan berkisar antara $0,250^{\circ}$ hingga $0,277^{\circ}$ dengan rata-rata kelerengan adalah hampir datar. Perairan Karangsong, Kabupaten Indramayu memiliki tipe pasang surut campuran condong harian ganda dengan nilai nilai Formzahl sebesar 0,57. nilai-nilai elevasi Perairan Karangsong meliputi MSL $64 \mathrm{~cm}$, HHWL 118,9 cm, LLWL 9,19 cm, LWL $10 \mathrm{~cm}$ dan HWL $110 \mathrm{~cm}$. Jenis Sedimen Dasar di Perairan Karangsong, Kabupaten Indramayu adalah pasir (silt) dan pasir lanauan (silty sand).
\end{abstract}

Kata kunci: Batimetri, Sedimen Dasar, Kelerengan, Perairan Karangsong.

\begin{abstract}
Karangsong Waters is coastral area that administratively is in the region of Indramayu regency is the important area for local society's economic. There is development planning and infrastructure maintenance in Karangsong Waters continuously it is needed there is research about batimetry, Slope and sea bottom sediment. The purpose of the research was to know the depth waters, profile of the water and also kinds of bottom sediments in the Karangsong Waters. The method in the research is quantitative method. Method of collecting the depth data and bottom sediments were do in the area which is considered to represent the characteristic of all the area. The result of the research showed the depth of Karangsong waters, regency of Indramayu about 1 meter until 11.8 meters with slope values about $0,250^{\circ}$ until $0,277^{\circ}$ with almost flat category. Karangsong water, regency of Indramayu has type of tidal skewed double daily with grade Formzahl about 0,57. the water karangsong elevation values such as MSL $64 \mathrm{~cm}$, HHWL 118,9 cm, LLWL $9,19 \mathrm{~cm}, \mathrm{LWL} 10 \mathrm{~cm}$ and HWL $110 \mathrm{~cm}$. Kinds of bottom sediments in the Karangsong water, Indramayu regency was sand and silty sand.
\end{abstract}

Keywords: Bathymetry, Sea Bottom Sediments, Slope, Karangsong Water.

\section{PENDAHULUAN}

Kabupaten Indramayu adalah daerah yang memiliki wilayah pesisir dengan garis pantai terpanjang di Provinsi Jawa Barat garis pantai sepanjang $114 \mathrm{~km}$. Menurut Satriadi (2012), kawasan pesisir adalah kawasan yang menjadi pusat berbagai kegiatan seperti tempat tinggal penduduk, budidaya, tempat wisata serta sebagai sarana perhubungan. Desa Karangsong merupakan merupakan salah satu kawasan pesisir yang secara administratif berada di wilayah Provinsi Jawa Barat tepatnya berada di Kecamatan Indramayu, Kabupaten Indramayu.

Perairan Karangsong merupakan perairan yang relatif sibuk dengan aktivitas bahari/kemaritiman yang cukup tinggi. Kegiatan 
tersebut diantaranya adalah aktivitas Tempat Pelelangan Ikan (TPI) dan Pangkalan Pendaratan Ikan (PPI) Karangsong, industri pembuatan kapal serta wisata Pantai Karangsong. Informasi perairan yang memadai sangat dibutuh untuk menunjang semua kegiatan di Perairan Karangsong. Informasi tersebut meliputi informasi kedalaman (batimetri) dan jenis sedimen dasar. Tujuan dari penelitian ini yaitu untuk mendapatkan data kedalaman (batimetri) dan sedimen dasar Perairan Karangsong. Penelitian dilakukan di Perairan Karangsong dibatasi oleh garis yang terhubung dari koordinat $108^{\circ} 21^{\prime} 40.86^{\prime \prime}$ BT - 108 $23^{\prime} 31.47^{\prime \prime}$ BT dan $6^{\circ} 17^{\prime} 46.18^{\prime \prime}$ LS - 6 $18^{\prime} 52.20^{\prime \prime}$ LS.

\section{MATERI DAN METODE}

Materi yang digunakan dalam penelitian ini menggunakan data primer berupa data hasil pemeruman dengan menggunakan Echosounder, data hasil pengamatan pasang surut selama pemeruman dan data jenis sedimen dasar. Data sekunder sebagai pelengkap data primer untuk mendukung penelitian ini meliputi data data pasang surut Karangsong bulan Juli 2015 dari Dinas Hidro-Oseanografi TNI AL, Peta Laut Dinas Hidro-Oseanografi skala 1:200.000 tahun 2003 lembar II Tanjung Priok hingga Cirebon, Peta Rupa Bumi Indonesia skala 1:25.000 tahun 1999 BAKOSURTANAL dan Peta Pola Arus Perairan Karangsong.

Metode pada penelitian ini menggunakan metode kuantitatif karena data penelitian berupa angka-angka dan analisis menggunakan statistik atau model (Sugiyono, 2009). Metode kuantitatif menghasilkan nilai yang tertera pada peta kedalaman atau batimetri dan jenis sedimen. Data kedalaman dan jenis sedimen dasar yang didapatkan kemudian dimodelkan dengan mengetahui kedalaman serta posisi jenis sedimen dasar. Pengolahan data dalam penelitian ini menggunakan metode admiralty untuk perhitungan pasang surut, pembuatan peta kontur menggunakan metode manual dengan menghubungkan titik pemeruman dengan nilai yang sama.

Metode pengamatan pasang surut secara langsung untuk verifikasi dilakukan selama pemeruman menggunakan palem pasut dengan interval 30 menit dan data pasang surut selama 30 hari dengan pencatatan interval selama 60 menit oleh instansi Dinas Hidro-Oseanografi. Data pasang surut diolah menggunakan metode
Admiralty untuk mendapatkan nilai komponen harmonik pasang surut $\left(\mathrm{S}_{0}, \mathrm{M}_{2}, \mathrm{~S}_{2}, \mathrm{~N}_{2}, \mathrm{~K}_{2}, \mathrm{~K}_{1}, \mathrm{O}_{1}\right.$, $\mathrm{P}_{1}, \mathrm{MS}_{4}$, dan $\mathrm{M}_{4}$ ) sehingga dapat dihitung nilai Formzahl untuk mengetahui tipe pasang surut dan digunakan sebagai koreksi data kedalaman laut untuk memperoleh kedalaman laut sebenarnya. Pengambilan data kedalalaman laut (pemeruman) Perairan Karangsong dilakukan menggunakan echosounder singlebeam, Garmin tipe GPSmap 585 dibantu dengan alat trasportasi pendukung yaitu perahu motor dengan kecepatan laju perahu 5 knot. Data yang diperoleh dari echosounder berupa titik yang memiliki nilai kedalaman (Gambar 1). Titik pemeruman memiliki bentuk sedemikian rupa untuk mempermudah dalam pembuatan garis kontur kedalaman Perairan Karangsong. Data pengukuran batimetri menggunakan echosounder selanjutnya dikoreksi terhadap kedudukan permukaan air laut (MSL, $\mathrm{Z}_{0}$, dan TWLt) pada saat dilakukan pengukuran dan dilakukan koreksi terhadap jarak tenggelam transduser (koreksi transduser) agar didapatkan kedalaman sebenarnya dari perairan. Nilai reduksi (koreksi) pengukuran didapatkan menggunakan persamaan berikut (Soeprapto, 1999):

$$
\mathrm{rt}=\mathrm{TWLt}-\left(\mathrm{MSL}+\mathrm{Z}_{0}\right)
$$

dimana:

rt : Besarnya reduksi (koreksi) yang diberikan kepada hasil pengukuran kedalaman pada waktu t.

TWLt: Kedudukan permukaan laut sebenarnya (true water level) pada waktu t.

MSL : Muka air laut rata-rata (Mean Sea Level).

$\mathrm{Z}_{0} \quad$ : Kedalaman muka surutan di bawah MSL.

Hasil dari persamaan (1) selanjutnya digunakan untuk mendapatkan kedalaman sebenarnya dengan menggunakan persamaan sebagai berikut (Soeprapto, 1999):

$$
\mathrm{D}=\mathrm{dT}-\mathrm{rt}
$$

dimana:

D : kedalaman sebenarnya

dT : kedalaman terkoreksi tranduser

rt : Reduksi (koreksi) pasang surut laut

Data kedalaman laut yang telah dihitung menggunakan persamaan (1) dan (2) diperoleh data kedalaman yang sebenarnya yang dapat digunakan sebagai dasar pembuatan garis kontur untuk mengetahui nilai kedalaman secara keseluruhan. 


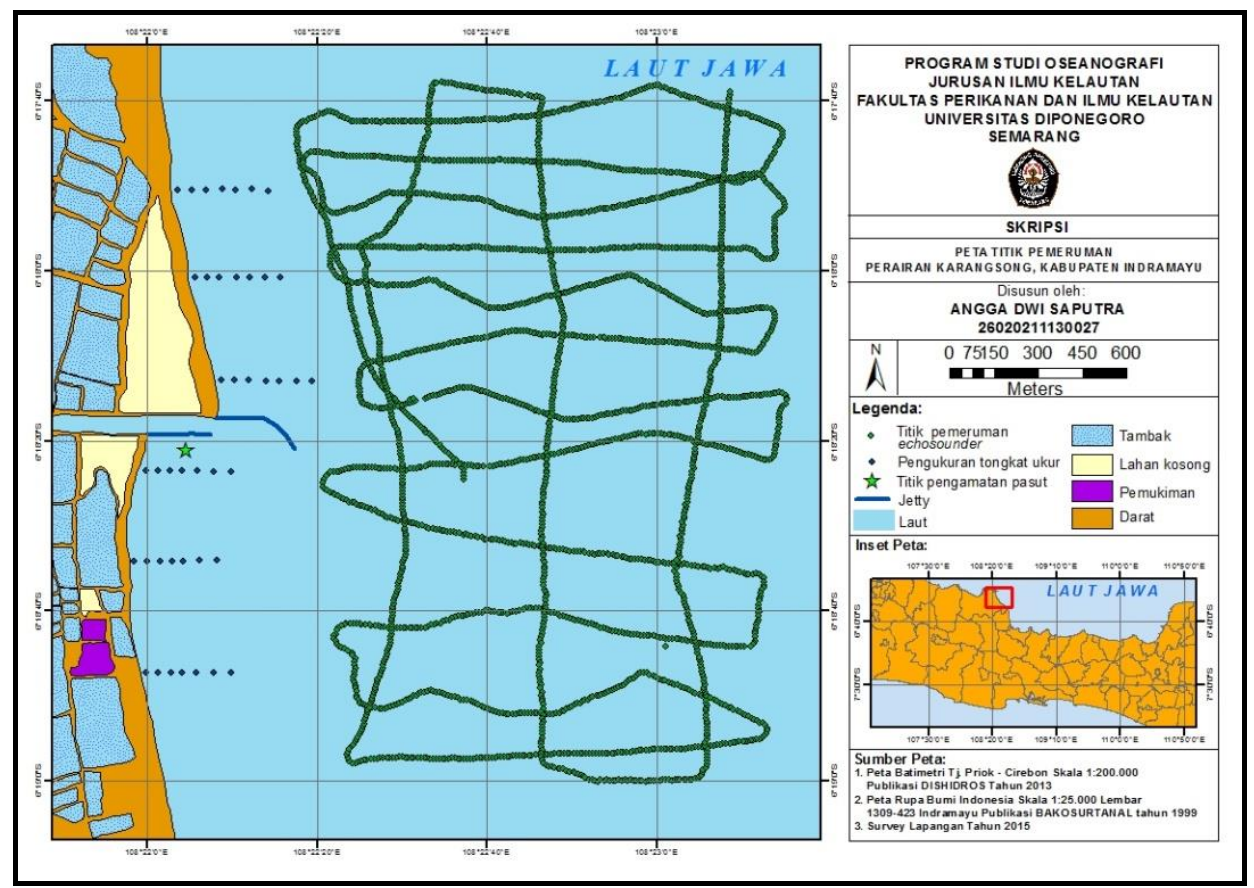

Gambar 1. Peta Hasil Titik-titik Pemeruman

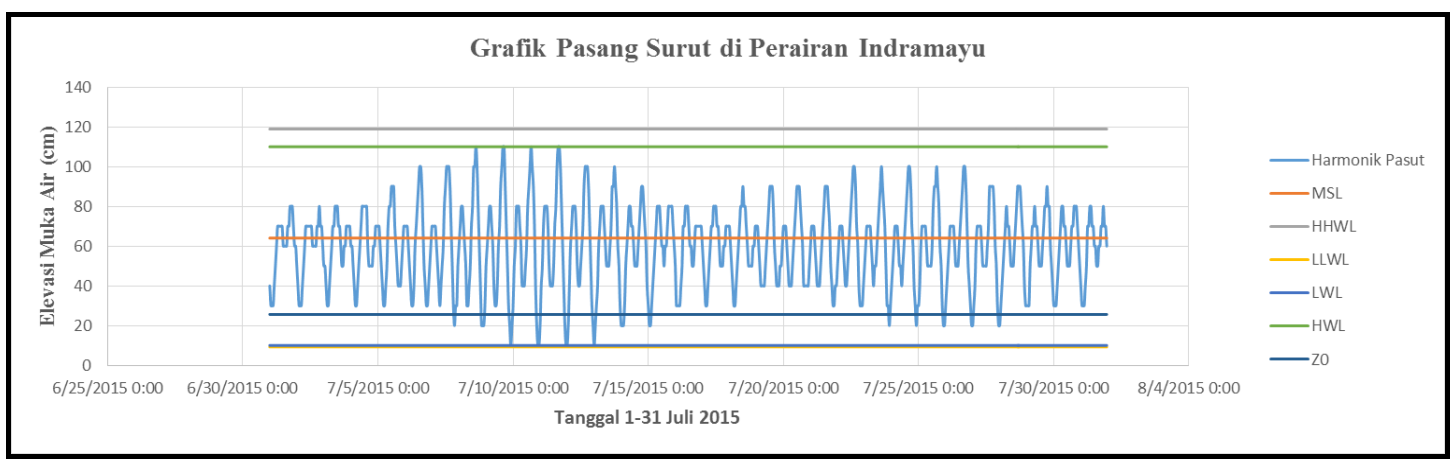

Gambar 2. Grafik Ketinggian Pasang Surut Perairan Karangsong.

Menghitung kemiringan (slope) menggunakan peta kontur batimetri yang sebelumnya digunakan dalam menggambarkan profil perairan yang terbagi atas tiga segmen yaitu A-A', B-B' dan C-C'. Penampang melintang pada lokasi penelitian dibuat menggunakan metode manual dengan cara eksagerasi. Menurut Tarigan (2014), pengukuran kemiringan lereng (slope) dilakukan terhadap peta batimetri menggunakan metode Wentworth, 1930 dengan persamaan:

$$
\operatorname{Tan} \alpha=\Delta \mathrm{H} / \mathrm{L}
$$

dimana :

$\alpha$ : besarnya sudut kemiringan dasar laut (slope)

L : jarak horizontal antara kedua garis kontur batimetri (m)

$\Delta \mathrm{h}$ : elevasi yang diperoleh antara dua kontur batimetri $(\mathrm{m})$
Penentuan jenis sedimen dasar Perairan Karangsong menggunakan analisa ukuran butir (Granulometri) yang diperoleh dengan cara penyaringan dan pemipetan menurut Holme dan Mc Intyre (1984) sampel sedimen yang nantinya akan diklasisfikasikan ukuran butirnya. Hasil ukuran butir kemudian diplotkan dalam segitiga shepard (1954) untuk proses penamaan sedimen dasar.

\section{HASIL DAN PEMBAHASAN}

Hasil pengolahan data pasang surut bulan Juli 2015 dengan pengolahan metode Admiralty menunjukkan nilai elevasi penting pasang surut Perairan Karangsong diantaranya Muka Air Rata - rata (Mean Sea Level) sebesar $64 \mathrm{~cm}$, Air Terendah (Low Water Level) sebesar $10 \mathrm{~cm}$, Air Tertinggi (High Water Level) sebesar $110 \mathrm{~cm}$, Air Rendah Terendah (Lowest Low Water Level) 
sebesar 9,19 cm, Air Tinggi Tertinggi (Highest High Water Level) sebesar 118,91 cm.

Nilai Formzahl yang diperoleh dari hasil analisa komponen harmonik pasang surut sebesar 0,57 yang menunjukan bahwa tipe pasang surut di perairan Pulau Biawak, Indramayu adalah bertipe campuran condong harian ganda yang berarti dalam satu hari terjadi dua kali air pasang dan dua kali air surut, tetapi tinggi dan periodenya berbeda.Hal tersebut ditunjukkan pada grafik pasang surut pada Gambar 2. Berdasarkan pengukuran kedalaman laut Perairan Karangsong menggunakan alat singlebeam echosounder Garmin tipe GPS map 585. Hasil titik pemeruman memiliki bentuk sedemikian rupa diakibatkan oleh beberapa faktor seperti faktor oseanografi fisika yaitu gelombang dan arus, manuver kapal yang terbatas dan area yang sulit diprediksi.

Hasil koreksi data kedalaman laut Perairan Karangsong menunjukkan bahwa kedalaman perairan berkisar antara 1-11 m. Penyajian peta batimetri berupa kontur yang disajikan pada Gambar 3, dengan interval kontur $1 \mathrm{~m}$ dimulai dari yang terkecil yaitu $1 \mathrm{~m}$ hingga yang terdalam $11 \mathrm{~m}$. Peta kontur batimetri Perairan Karangsong memiliki garis kontur yang cenderung renggang yang mengindikasikan bahwa Perairan Karangsong relatif landai/hampir datar.

Penentuan nilai kelerengan Perairan karangsong terbagi atas tiga segmen yaitu A-A',
B-B' dan C-C'. Hasil perhitungan dari tiga segmen tersebut diperoleh nilai kelerengan berkisar mulai dari $0,250^{\circ}$ hingga $0,277^{\circ}$. Nilai kelerengan tersebut menurut Zuidam (1985) masuk dalam kategori landai atau hampir rata yang sesuai dengan hasil gambaran kontur kedalaman yang menunjukkan bahwa Perairan Karangsong relatif landai/hampir rata Nilai kelerengan Perairan Karangsong ditunjukkan pada Tabel 1.

Pengambilan sampel sedimen dasar Perairan Karangsong dilakukan di 15 titik yang dianggap mewakili keseluruhan area yang diteliti. Hasil dari pengolahan sedimen dasar Perairan Karangsong didapatkan bahwa Jenis sedimen dasar didominasi oleh dua jenis sedimen dasar yaitu jenis sedimen dasar pasir dan sedimen dasar pasir lanauan. Sedimen dasar pasir berada pada kedalaman $1 \mathrm{~m}$ hingga kedalaman $7 \mathrm{~m}$ sedangkan sedimen dasar pasir lanauan berada pada kedalaman 8 m hingga $11 \mathrm{~m}$. Keberadaan sedimen dasar tersebut kemungkinan dipengaruhi oleh beberapa faktor seperti faktor oseanografi fisika yaitu arus, pasang surut dan gelombang, faktor sedimen dari sungai dan faktor kegiatan manusia. Posisi dari sedimen dasar Perairan Karangsong diintepretasikan dalam bentuk Peta Jenis Sedimen Dasar (Gambar 4). Koordinat serta nama dari jenis sedimen dasar ditunjukkan pada Tabel 2.

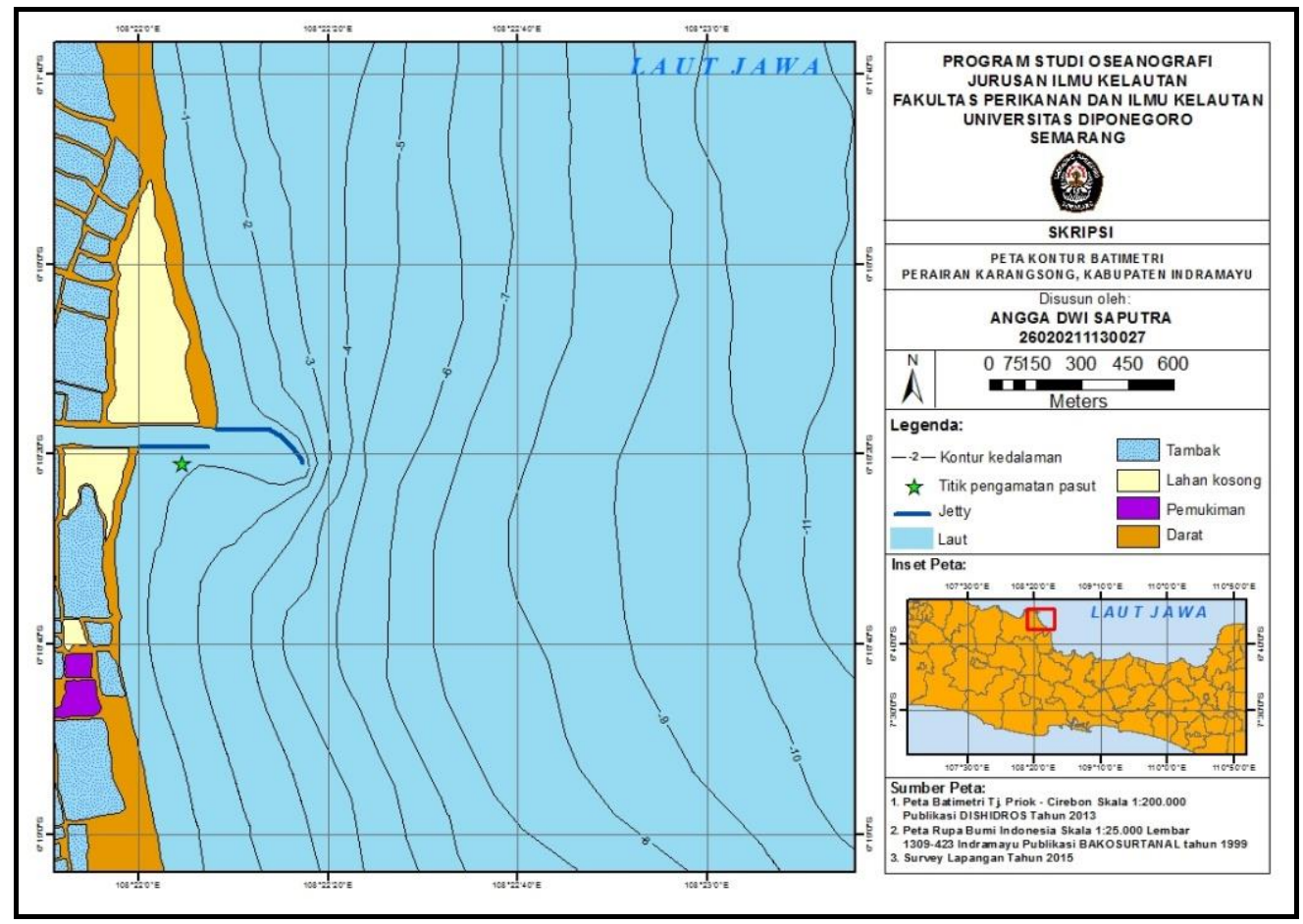

Gambar 3. Peta Kontur Batimetri Perairan Karangsong. 


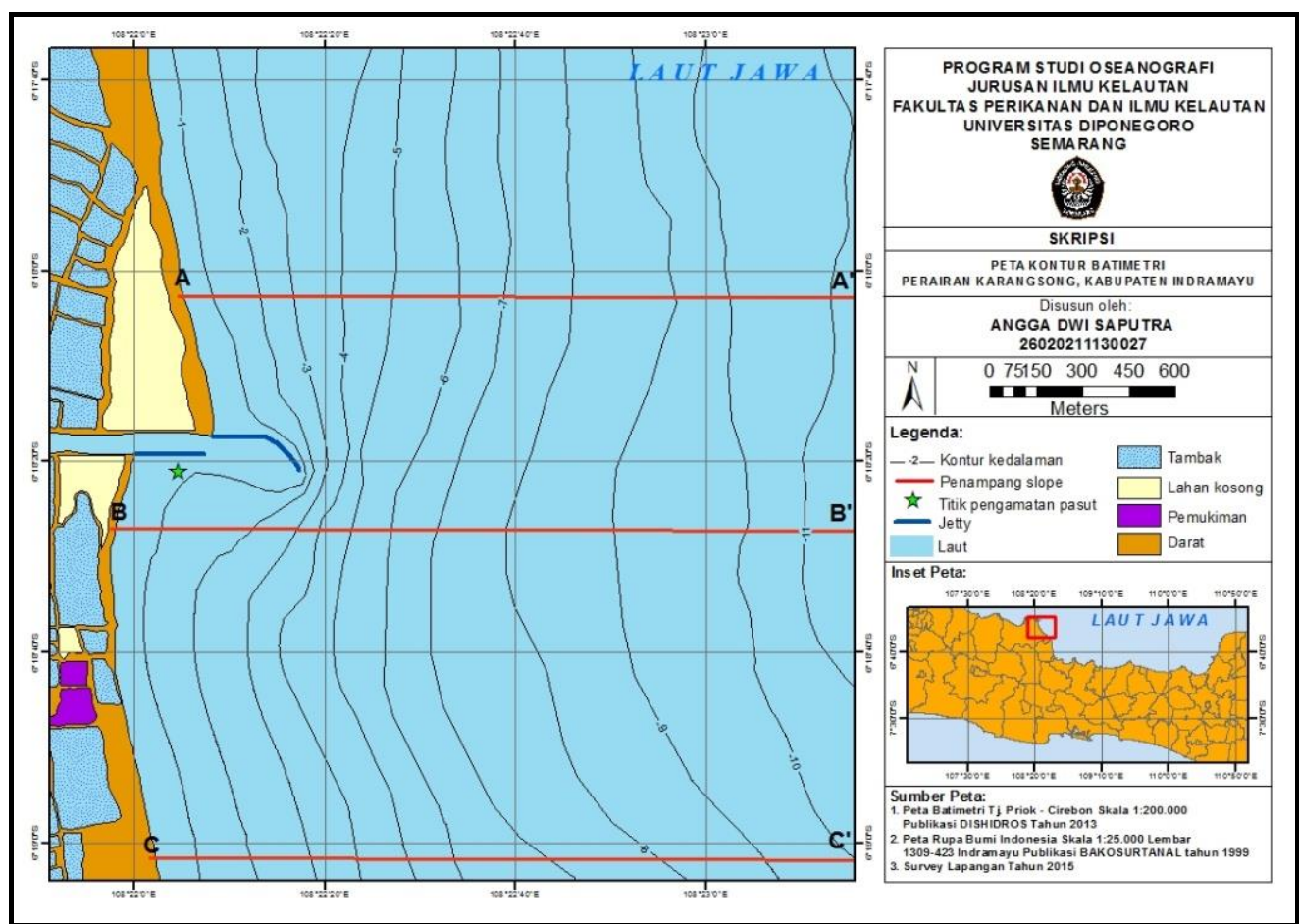

Gambar 4. Peta Penampang Melintang Profil Perairan Karangsong

Tabel 1. Nilai Kelerengan Perairan Karangsong

\begin{tabular}{llcl}
\hline No & Profil & Nilai Slope $\left({ }^{\circ}\right)$ & Jenis Kelerengan \\
\hline 1 & A-A & 0,277 & Rata/Hampir rata \\
2 & B-B' & 0,250 & Rata/Hampir rata \\
3 & C-C' & 0,266 & Rata/Hampir rata \\
\hline
\end{tabular}

Tabel 2. Jenis Sedimen Dasar Perairan karangsong

\begin{tabular}{|c|c|c|c|}
\hline \multirow{2}{*}{ Stasiun } & \multicolumn{2}{|c|}{ Koordinat Titik-titik Sampel } & \multirow{2}{*}{ Jenis Sedimen Dasar } \\
\hline & Bujur & Lintang & \\
\hline 1 & $108^{\circ} 22^{\prime} 28.38^{\prime \prime} \mathrm{E}$ & $06^{0} 18 ’ 57.72 ” S$ & Pasir \\
\hline 2 & $108^{\circ} 22^{\prime} 25.33^{\prime \prime} \mathrm{E}$ & $06^{0} 18 ’ 37.79 ” \mathrm{~S}$ & Pasir \\
\hline 3 & $108^{\circ} 22^{\prime} 28.92^{\prime \prime} \mathrm{E}$ & $06^{0} 18^{\prime} 27.38^{\prime \prime} \mathrm{S}$ & Pasir \\
\hline 4 & $108^{\circ} 22^{\prime} 26.52^{\prime \prime} \mathrm{E}$ & $06^{0} 18^{\prime} 03.89^{\prime \prime} \mathrm{S}$ & Pasir \\
\hline 5 & $108^{\circ} 22^{\prime} 26.82^{\prime \prime} \mathrm{E}$ & $06^{0} 17 ' 49.91 ” S$ & Pasir \\
\hline 6 & $108^{\circ} 22^{\prime} 47.17^{\prime} \mathrm{E}$ & $06^{0} 19^{\prime} 05.15^{\prime \prime} \mathrm{S}$ & Pasir \\
\hline 7 & $108^{\circ} 22^{\prime} 40.88^{\prime \prime} \mathrm{E}$ & $06^{0} 188^{\prime} 37.20^{\prime \prime S}$ & Pasir \\
\hline 8 & $108^{\circ} 22^{\prime} 45.07^{\prime} \mathrm{E}$ & $06^{0} 18^{\prime} 21.14 ” S$ & Pasir \\
\hline 9 & $108^{\circ} 22^{\prime} 43.57^{\prime} \mathrm{E}$ & $06^{0} 18^{\prime} 01.21 \% \mathrm{~S}$ & Pasir \\
\hline 10 & $108^{\circ} 22^{\prime} 41.77^{\prime \prime} \mathrm{E}$ & $06^{0} 17^{\prime} 47.23 " \mathrm{~S}$ & Pasir \\
\hline 11 & $108^{\circ} 23^{\prime} 20.38^{\prime \prime} \mathrm{E}$ & $06^{0} 19^{\prime} 00.69^{\prime \prime} \mathrm{S}$ & Pasir Lanauan \\
\hline 12 & $108^{\circ} 23^{\prime} 13.20^{\prime \prime} \mathrm{E}$ & $06^{0} 188^{\prime} 57.72 ” \mathrm{~S}$ & Pasir Lanauan \\
\hline 13 & $108^{\circ} 23^{\prime} 15.89^{\prime \prime} \mathrm{E}$ & $06^{0} 18^{\prime} 29.78^{\prime \prime S}$ & Pasir Lanauan \\
\hline 14 & $108^{\circ} 23^{\prime} 12.00^{\prime \prime} \mathrm{E}$ & $06^{0} 18^{\prime} 01.51 ” S$ & Pasir Lanauan \\
\hline 15 & $108^{\circ} 23^{\prime} 10.80^{\prime \prime} \mathrm{E}$ & $06^{0} 17^{\prime} 43.06^{\prime \prime} \mathrm{S}$ & Pasir Lanauan \\
\hline
\end{tabular}




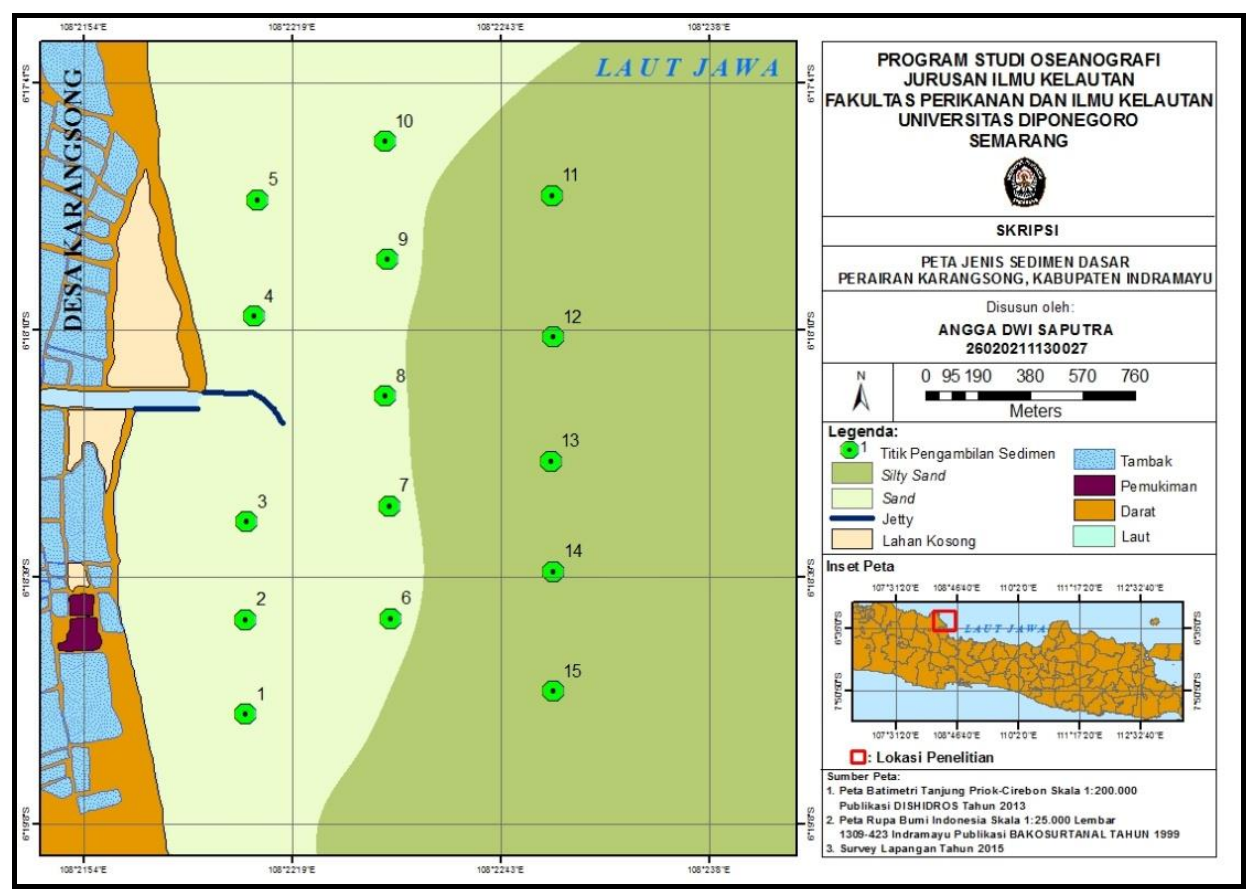

Gambar 5. Peta Jenis Sedimen Dasar Perairan Karangsong.

\section{SIMPULAN}

Berdasarkan hasil pengolahan dan analisis data maka dapat disimpulkan bahwa data pasang surut di Perairan Pulau Biawak, diperoleh nilai MSL $=64, \quad$ HHWL $=118,91, \quad H W L=110$, LLWL $=9,19, \quad L W L=10$ dan nilai Formzahl sebesar 0,57 sehingga termasuk dalam tipe pasang surut campuran condong harian ganda (semi diurnal). Kedalaman Perairan Karangsong memiliki nilai kedalaman $1 \mathrm{~m}$ sampai $11 \mathrm{~m}$ dengan kelerengan bernilai $0,250^{\circ}$ hingga $0,277^{\circ}$ dengan kategori kelerengan landai/hampir datar. Jenis sedimen dasar Perairan Karangsong didominasi oleh sedimen dasar pasir dan sedimen dasar pasir lanauan.

\section{DAFTAR PUSTAKA}

Holme N. A. And Mc Intyre, A. D. 1984. Methods for the Study of Marine Benthos. Backwall Scientific Publication, Oxford, 387 hlm.

Satriadi, Alfi. 2012. Studi Batimetri dan Jenis Sedimen Dasar Laut di Perairan Marina,
Semarang, Jawa Tengah. Buletin Oseanografi., 01:53-62.

Soeprapto. 1999. Survei Hidrografi.Gajah Mada University Press. Yogyakarta. $202 \mathrm{hlm}$.

Sugiyono. 2009. Metode Penelitian Kuantitatif Kualitatif. Alfabeta, Bandung.

Supriadi. A. 2014. Pemetaan Batimetri untuk Alur Pelayaran Pelabuhan Penyebrangan Mororejo, Kabupaten Kendal. Jurnal Oseanografi Undip., 3(2):284-293.

Tarigan, Suranta. 2014. Studi Pemetaan Batimetri menggunakan Multibeam Echosounder di Perairan Pulau Komodo, manggarai Barat, Nusa Tenggara Timur. Jurnal Oseanografi Undip., 3(2):257-266.

Zuidam, R. A., Van. 1985. Aerial PhotoInterpretation Terrain Analysis and Geomorphology Mapping. Smith Publisher The Hague, ITC. 